\title{
Producción de astaxantina bajo factores de estrés utilizando un biorreactor a escala de laboratorio de $5 \mathrm{~L}$
}

\author{
Astaxanthin production under stress factors using a 5L \\ laboratory scale bioreactor
}

Ana Graciela Lancheros Díaz , Luis Eduardo Díaz Barrera², Judith Elena Camacho Kurmen ${ }^{3}$

\section{Resumen}

Introducción. Haematococcus pluvialis es una microalga que produce astaxantina, un betacaroteno y antioxidante muy usado en la industria. Para obtener una mayor producción de astaxantina se planteó como objetivo utilizar diferentes factores de estrés, en un biorreactor a escala de laboratorio de 5 litros. Metodología. Se cultivó la microalga en el medio RM, $\mathrm{pH} 6,8$, temperatura $20 \pm 2^{\circ} \mathrm{C}$, aire filtrado, iluminación con lámparas blancas $20 \mathrm{~h}$ luz/4h oscuridad, irradianza $70 \mu \mathrm{E} \mathrm{m}^{-2} \mathrm{~s}^{-1}$, diferentes concentraciones de acetato de sodio y cloruro de sodio. Se determinó crecimiento celular, cambios morfológicos y cuantificación de astaxantina y clorofila por espectrofotometría. Se realizó un análisis estadístico utilizando ANOVA (95\%). Resultados. Utilizando $0,299 \mathrm{mg} / \mathrm{L}$ de acetato de sodio se obtuvo un crecimiento celular de $2,0 \times 10^{4} \mathrm{Cel} / \mathrm{mL}$ y una concentración de astaxantina de $2,530 \mu \mathrm{g} / \mathrm{mL}$, mientras que con $1,6 \mathrm{mg} / \mathrm{L}$ de acetato de sodio el crecimiento celular fue de $3,5 \times 10^{4} \mathrm{Cel} /$ $\mathrm{mL}$ y una concentración de astaxantina de $1,9 \mu \mathrm{g} / \mathrm{ml}$. El tratamiento al cual se le adicionó 1,6 g/L de acetato de sodio y 6,4 g/L de cloruro de sodio presentó la mayor producción astaxantina $7,3 \mu \mathrm{g} / \mathrm{ml}$. El tratamiento con acetato de sodio $0,320 \mathrm{~g} / \mathrm{L}+$ cloruro de sodio

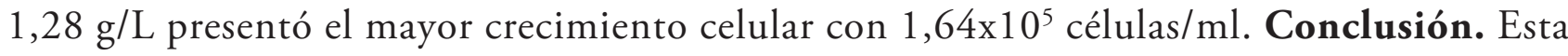
investigación destaca la importancia de cultivar inicialmente la microalga utilizando el biorreactor Tecferm de 5 litros y después de su fase exponencial someterla a factores de estrés con acetato de sodio y cloruro de sodio lográndose así la mayor producción de astaxantina $7,325 \mu \mathrm{g} / \mathrm{ml}$.

Palabras claves: microalgas, crecimiento celular, estrés, betacaroteno, clorofila, acetato de sodio.

\footnotetext{
1. CvLAC: https://scienti.minciencias.gov.co/cvlac/visualizador/generarCurriculoCv.do?cod_rh $=0000482730$ Google Scholar: https://scholar.google.com/citations?view_op=list_works\&hl=es\&user=nLa_f7UAAAAJ ORCID: https://orcid.org/0000-0002-5799-0282

2. CVLAC: http://scienti.colciencias.gov.co:8081/cvlac/visualizador/generarCurriculoCv.do?cod_rh $=0000059498$ Google Scholar: https://scholar.google.com/citations?user=0tS_Nr8AAAAJ\&hl=es ORCID: https://orcid.org/0000-0002-9588-9935

3. CvLAC: https://scienti.colciencias.gov.co/cvlac/visualizador/generarCurriculoCv.do?cod rh $=0000421863$ Google Scholar: https://scholar.google.com/citations?user=kd0ccMIAAAAJ\&hl=en ORCID: https://orcid.org/0000-0002-8880-1501

https://doi.org/10.22490/24629448.5498
} 


\section{Abstract}

Introduction. Haematococcus pluvialis is a microalgae that produces astaxanthin, a beta-carotene and antioxidant widely used in industry. In order to obtain a higher production of astaxanthin, the objective was to use different stress factors, in a 5-liter laboratory-scale bioreactor. Methodology. The microalgae was cultivated in the RM medium, $\mathrm{pH} \mathrm{6.8,}$ temperature $20 \pm 2{ }^{\circ} \mathrm{C}$, filtered air, illumination with white lamps $20 \mathrm{~h}$ light/4h darkness, irradiance $70 \mu \mathrm{E} \mathrm{m}^{-2} \mathrm{~s}^{-1}$, different concentrations of sodium acetate and chloride of sodium. Cell growth, morphological changes and quantification of astaxanthin and chlorophyll were determined by spectrophotometry. Statistical analysis was performed using ANOVA (95\%). Results. Using $0.299 \mathrm{mg} / \mathrm{L}$ of sodium acetate a cell growth of $2.0 \times 10^{4} \mathrm{Cel} / \mathrm{mL}$ and an astaxanthin concentration of $2.530 \mu \mathrm{g} / \mathrm{mL}$ were obtained, while with $1.6 \mathrm{mg} / \mathrm{L}$ of sodium acetate the cell growth It was $3.5 \times 10^{4} \mathrm{Cel} / \mathrm{mL}$ and an astaxanthin concentration of $1.9 \mu \mathrm{g} / \mathrm{mL}$. The treatment to which $1.6 \mathrm{~g} \mathrm{~L}$ of sodium acetate and $6.4 \mathrm{~g} / \mathrm{L}$ of sodium chloride were added showed the highest astaxanthin production, $7.3 \mu \mathrm{g} / \mathrm{ml}$. Treatment with $0.320 \mathrm{~g} / \mathrm{L}$ sodium acetate $+1.28 \mathrm{~g} / \mathrm{L}$ sodium chloride showed the highest cell growth with $1.64 \times 10^{5}$ cells $/ \mathrm{ml}$. Conclusion. This research highlights the importance of initially cultivating the microalgae using the 5 -liter Tecferm bioreactor and, after its exponential phase, subjecting it to stress factors with sodium acetate and sodium chloride, thus achieving the highest production of $7.325 \mu \mathrm{g} / \mathrm{ml}$ astaxanthin.

Keywords: microalgae, cell growth, stress, beta-carotene, chlorophyll, sodium acetate.

\section{Introducción}

Dentro de la biodiversidad se encuentran las microalgas que son fuente de un gran número de compuestos bioactivos de interés industrial, como los carotenoides que se utilizan como colorantes naturales en alimentación animal y humana, así como en la industria farmacéutica, cosmética y en la acuicultura. Además, se han propuesto como agentes efectivos en la prevención de una variedad de enfermedades, debido a su capacidad antioxidante, inmunoreguladora, anti-inflamatoria y anti-cancerígena.
El cultivo de microalgas también tiene la capacidad de metabolizar los nutrientes del medio en donde habitan, los cuales se utilizan para la biorremediación de aguas residuales que son productos derivados de la actividad industrial, doméstica y la explotación agropecuaria, los cuales no deben ser vertidos directamente a los cuerpos de agua debido a los problemas sanitarios que puedan generar. Se tiene como ejemplo el Cr VI que es un elemento tóxico y con potencial carcinógeno el cual debe ser removido de todo tipo de desecho industrial antes de su disposición final en ríos y rellenos 
sanitarios por lo que la implementación de métodos microbiológicos puede darle un nuevo enfoque a los métodos de reducción utilizados actualmente (28).

El alga unicelular $H$. pluvialis ha sido estudiada exhaustivamente debido a su capacidad para acumular astaxantina y otros carotenoides relacionados. La acumulación de este carotenoide en la microalga está relacionado con la evolución de diferentes etapas de la célula vegetativa a la aplanospora en el ciclo de la microalga, pero esta transición solo se da cuando esta ha sido sometida a diferentes condiciones de estrés. Actualmente se conocen diferentes condiciones de estrés como limitación de nitrógeno, deficiencia de magnesio, alta intensidad de luz, falta de fósforo y estrés salino, las cuales han demostrado ser una fuente importante de carbono, lo que mejora el crecimiento y la carotenogénesis, ya que afectan la ruta de la fotosíntesis y aumentan la expresión genética de la enzima BKT.

La realización de este proyecto pretende aprovechar los avances de la ciencia y la tecnología basados en la utilización de las propiedades de los organismos en particular en los niveles celular y subcelular, para generar y adaptar tecnologías que permitan obtener compuestos bioactivos a través de bioprocesos. Es por esto que una estrategia promisoria para mejorar la producción de astaxantina en el $H$. pluvialis, es el estudio de las rutas metabólicas y su regulación, con el fin de optimizar las condiciones de crecimiento, su desarrollo y producción, ya que la utilización del $H$. pluvialis tiene sus dificultades en el momento del cultivo y de obtener el pigmento en cantidades de interés debido a su ciclo celular complejo. Uno de los principales inconvenientes es que se trata de un producto del metabolismo secundario. Durante el crecimiento activo, no se produce síntesis de astaxantina, solo cuando cesa la división celular se inicia su síntesis y se acumula en grandes cantidades.

H. pluvialis tiene también unas tasas de crecimiento bajas lo que debilita sus posibilidades de uso como fuente natural del pigmento, además es susceptible a la contaminación. Estas características requieren cultivos en sistemas cerrados, los cuales ofrecen ventajas como mejor control del cultivo, protección de la contaminación ambiental y producción de gran cantidad de biomasa, así como el desarrollo de un medio de cultivo óptimo para su crecimiento ya que el uso de una adecuada tecnología de cultivo incrementa la producción de biomasa hasta niveles óptimos para la producción del pigmento. De igual forma, un mayor entendimiento de las bases moleculares de la relación -condiciones de estrés-inducción- acumulación de astaxantina en $H$. pluvialis, podría ser útil para aumentar la productividad de astaxantina.

Es por esto que la presente investigación busca producir astaxantina, ya que actualmente se sintetiza químicamente y esta forma sintética es de alto costo 2500 dólares por kilogramo, además esta ha sido prohibida en el mercado por la Administración 
de Drogas y Alimentos de los Estados Unidos (FDA) debido a su baja biodisponibilidad y seguridad. Estas preocupaciones son debidas a la estereoquímica diferente y el potencial arrastre de los intermedios de síntesis, haciendo que la astaxantina natural de H. pluvialis sea una buena opción de buena calidad frente a la forma química y con respecto a los otros microorganismos que son capaces de producirla.

\section{Materiales y métodos}

\section{Proceso de escalamiento}

Microorganismo: Haematococcus pluvialis UTEX, cepa de referencia (colección de cultivos de algas, Universidad de Texas, Austin TX, USA). Se mantuvo la cepa en medio sólido y líquido Volvox-MES (sugerido por la UTEX), a baja irradianza, temperatura $15-20^{\circ} \mathrm{C}$.

La activación de la cepa se realizó en medio líquido Volvox-MES, a baja irradianza y temperatura ambiente.

\section{Monitoreo de las células del H. pluvialis durante el cultivo}

Para control de calidad de la cepa y del cultivo, se tuvo en cuenta que se trabajó con una cepa de referencia de la UTEX, la cual se encuentra caracterizada previamente. Para ver pureza de la cepa y del cultivo se monitoreó, utilizando un microscopio para determinar el color, tamaño, viabilidad y morfología de las células y con cámara de Neubauer se determinó el promedio de número de células y tamaño celular. Además se realizó control del $\mathrm{pH}$.

\section{Preparación del Inoculo}

Para preparar el inoculo se tomó una muestra de la solución stock de la cepa de referencia de la UTEX y se transfirió asépticamente a un erlenmeyer de $500 \mathrm{ml}$ que contenía 200 $\mathrm{ml}$ de medio Volvox-MES fresco (Tabla No 1) y estéril bajo continua iluminación, $\mathrm{CO}_{2}$ $5 \%$ en aire, agitación continua a $25^{\circ} \mathrm{C}$ por 4 días. Para todos los experimentos un cultivo de 4 días fue usado como el inoculo (en la fase exponencial de crecimiento).

Para establecer la cantidad de inoculo a utilizar se hizo un conteo celular y con esta información se procedió a realizar los cálculos necesarios para saber el volumen a adicionar del inoculo a los reactores en sistema batch.

Tabla 1. Composición de medio MES volvox (29)

\begin{tabular}{|l|}
\hline MEDIO VOLVOX-MES (UTEX) \\
\hline $\mathrm{Ca}(\mathrm{NO} 3) 2.4 \mathrm{H} 2 \mathrm{O} 11,8 \mathrm{~g} / 100 \mathrm{ml} \mathrm{H} 2 \mathrm{O}$ \\
$\mathrm{MgSO} 4.7 \mathrm{H} 2 \mathrm{O} \mathrm{g} / 100 \mathrm{ml}$ \\
$\mathrm{Na} 2 \mathrm{glicerofosfato} .5 \mathrm{H} 2 \mathrm{O} 0,05 \mathrm{G} / \mathrm{L}$ \\
$\mathrm{KCl} \quad 0,05 \mathrm{G} / \mathrm{L}$ \\
$\mathrm{MES} \quad 1,95 \mathrm{G} / \mathrm{L}$ \\
$\mathrm{PIV} \mathrm{METAL} \mathrm{SLN} .6 \mathrm{ml} / \mathrm{L}$ \\
$\mathrm{NH} 4 \mathrm{Cl} \quad 0,026 \mathrm{G} / \mathrm{l}$ \\
Vitamina B12 $\quad 1 \mathrm{ml} / \mathrm{L} \mathrm{H} 2 \mathrm{O}$ \\
$\mathrm{HEPES}$ buffer $\quad$ \\
$\mathrm{BIOTINA} 1 \mathrm{ml} / \mathrm{L}$ \\
\hline pH $\quad 6,7$ \\
\hline
\end{tabular}

Fuente: García Martin Laura (5). 


\section{Sistema de cultivo}

Se realizó el cultivo de $H$. pluvialis en el biorreactor TEC - FERM a escala de laboratorio de 5 litros en sistema batch en el medio RM.

\section{Condiciones de cultivo}

Condiciones estándar: $\mathrm{pH} 7$, ciclo luz/oscuridad 20h: $4 \mathrm{~h}$, temperatura $25^{\circ} \mathrm{C}$, agitación continua, $\mathrm{CO}_{2} 5 \%$ en aire, iluminación con lámparas fluorescentes blancas (Tlt 20w/54RS marca Philips). El proceso se desarrolló bajo condiciones normales del medio y ciclo luz/oscuridad $18 \mathrm{~h}$ : $6 \mathrm{~h}$ y condiciones de estrés con concentraciones de acetato de sodio y acetato de sodio + cloruro de sodio en $\mathrm{mg} / \mathrm{L}$.

El medio RM estéril con el $\mathrm{pH}$ ajustado se adicionó al biorreactor hasta un volumen de 2 Litro (Figura 1).

- Se procedió a adicionar el inoculo de la microalga al 10\% (1x 104 Células/ml).

- Se realizó el montaje bajo las condiciones establecidas.

- Toma de muestra cada tercer día en forma aséptica.

- Conservación de las muestras en solución formasalina (1:9), en una proporción $1: 1$, se tomaron $500 \mu \mathrm{l}$ y se realizó control del cultivo (conteo celular y morfología) y el resto de muestra se utilizó para medición de $\mathrm{pH}$.
- Se llevó control de temperatura, pH, agitación, $\mathrm{CO}_{2}$ en aire, ciclo luz/oscuridad, medios.

- Tiempo del estudio 20 - 40 días

Fase 1 Crecimiento de H. Pluvialis: Se evalúo el crecimiento de $\mathrm{H}$. pluvialis UTEX 2505 bajo las condiciones de cultivo establecidas como medio RM, $\mathrm{pH} 6.8$, ciclo luz/oscuridad 16h: $8 \mathrm{~h}$, temperatura $20 \pm 2^{\circ} \mathrm{C}$, agitación manual una vez al día durante 10 segundos, iluminación con lámparas fluorescentes blancas (Tlt 20w/54RS marca Philips), irradianza de $70 \mu \mathrm{E} \mathrm{m} \mathrm{m}^{-2} \mathrm{~s}^{-1}$ y aire filtrado. Las condiciones de estrés utilizadas fueron estrés salino usando diferentes concentraciones de acetato y cloruro de sodio, combinándolas con luz blanca alta. Se realizó conteo celular en Cámara de Neubauer por triplicado. Se realizó curva de crecimiento a partir de los resultados. Se aplicó modelo logístico por Dmfit.

Fase 2 Cambios morfológicos celulares. Se realizó el monitoreo de la microalga utilizando un microscopio de luz para determinar el color, tamańo, viabilidad y morfología de las células, realizando registro fotográfico a 10x y 40x.

\section{Fase 3 Cuantificación de astaxantina y} clorofila. Se utilizó método APHA, 1992. Análisis estadístico de los datos. Se realizó un análisis de varianza ANOVA (95\%) para ver diferencias significativas entre tratamientos, usando Excel 2016. 


\section{Resultados}

En el primer tratamiento realizado en el biorreactor TEC - FERM de 5 L (Figura 1), se utilizó una concentración de 0.299 $\mathrm{mg} / \mathrm{L}$ de acetato de sodio en el medio RM, bajo las condiciones de trabajo previamente establecidas, obteniéndose un recuento de inicial de $1,0 \times 10^{4} \mathrm{Cel} / \mathrm{mL}$ y un recuento final del $1 \times 10^{3} \mathrm{Cel} / \mathrm{mL}$ durante los 34 días del estudio. $\mathrm{El} \mathrm{pH}$ presentó fluctuaciones entre 6,7 a 7,5 , cercano a la neutralidad.

Figura 1. Biorreactor TEC-FERM.

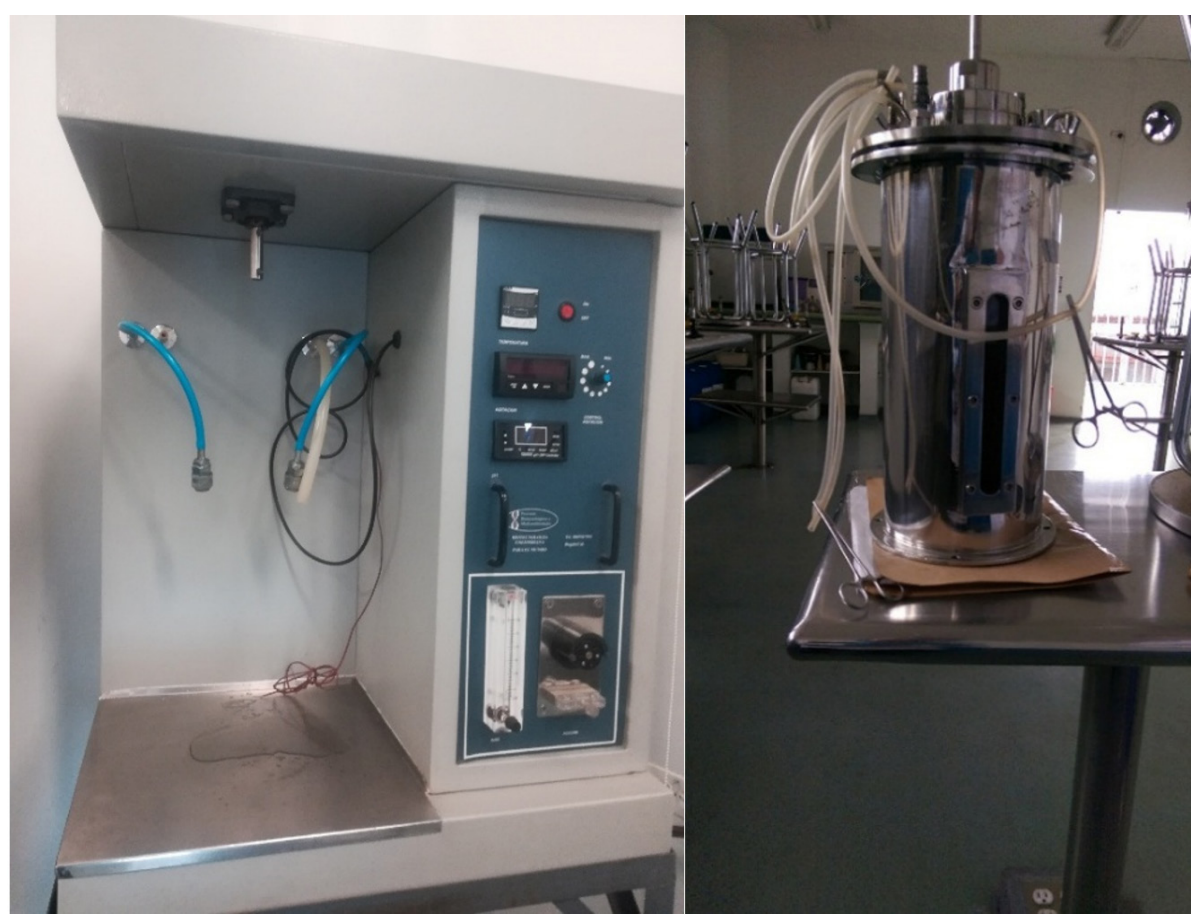

Fuente: García Martin Laura (5).

El recuento celular obtenido con el tratamieno de $0,299 \mathrm{mg} / \mathrm{L}$ de acetato de sodio indica que la microalga presenta crecimiento exponencial hasta el día 13 con un recuento celular de $2,0 \times 10^{4} \mathrm{Cel} / \mathrm{mL}$ hasta el dia 20 , cuando empieza a disminuir el recuento celular hasta el dia 34 con un recuento celular de $1 \times 10^{3} \mathrm{Cel} / \mathrm{mL}$ (Figura 2).

Las tendencias de crecimiento fueron ajustadas al modelo logístico mediante transfor- mación de los valores de $\mathrm{Y}$ a los que se les calculó su logaritmo en base 10 para obtener $\log$ vs $t$ del crecimiento celular. La idea de realizar el ajuste fue ajustar los datos y determinar si existían diferencias significativas en la velocidad de crecimiento de los tratamientos ensayados. 
Figura 2. Curva crecimiento celular con $0,299 \mathrm{mg} / \mathrm{L}$ de acetato de sodio.

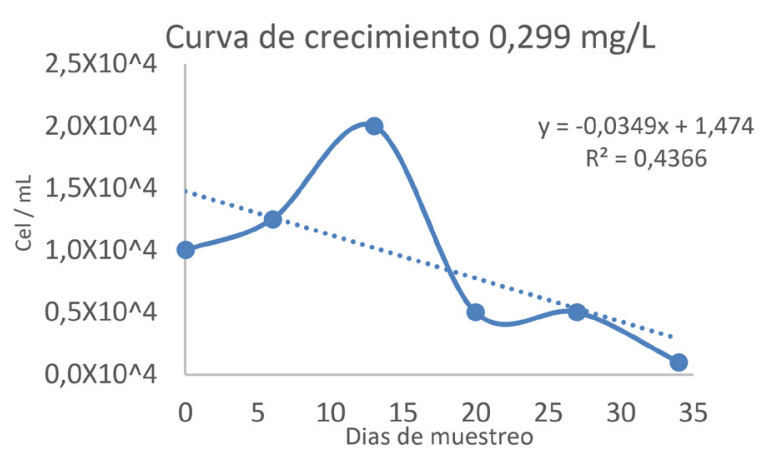

Fuente: García Martin Laura (5).

Figura 3. Curva crecimiento celular con 1,6 mg/L de acetato de sodio.

Curva de crecimiento $1,6 \mathrm{mg} / \mathrm{dL}$

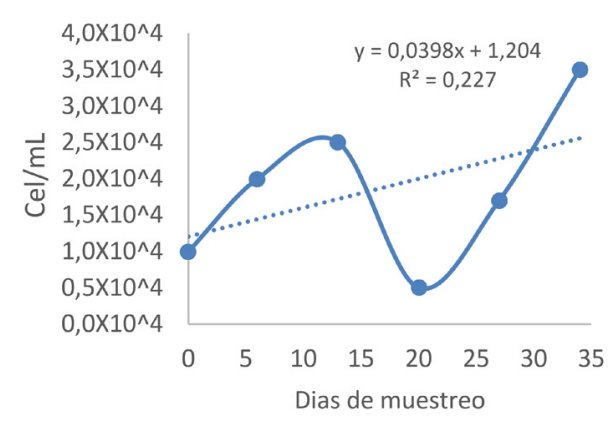

Fuente: García Martin Laura (5).

En el recuento celular obtenido con el tratamieno de $1,6 \mathrm{mg} / \mathrm{L}$ de acetato de sodio se observó de nuevo que la microalga presenta un crecimiento exponencial hasta el día 13, donde alcanzó un recuento de $2,5 \times 10^{4} \mathrm{Cel} /$ $\mathrm{mL}$ y comienza a disminuir hasta el dia 20 , el día 27 presenta un recuento de 1,7 $\mathrm{x} 10^{4} \mathrm{Cel} / \mathrm{mL}$. En el dia 34 se obtiene un au- mento del recuento celular de $3,5 \times 10^{4} \mathrm{Cel} /$ $\mathrm{mL}$, valor superior al del dia 13 , día en el que finaliza la fase exponencial de la microalga (Figura 3). El medio de cultivo con mayor velocidad especifica de crecimiento fue el RM con concentración de acetato 0,299 $\mathrm{mg} / \mathrm{L}$ con una velocidad de crecimiento de 0.029 Células/día (Tabla 2).

Tabla 2. Velocidad de crecimiento de los montajes analizados.

\begin{tabular}{|l|l|l|l|l|l|}
\hline Medio de cultivo & Numero de datos & Dato mínimo & Dato máximo & $\begin{array}{l}\text { Velocidad de } \\
\text { crecimiento }\end{array}$ & $\begin{array}{l}\text { Coeficiente de } \\
\text { determinación }\end{array}$ \\
\hline RM y acetato $0,299 \mathrm{mg} / \mathrm{L}$ & 6 & 4.204 & 4,300 & 0,029 Cel/día & $79 \%$ \\
\hline RM y acetato $1,6 \mathrm{mg} / \mathrm{L}$ & 6 & 4.301 & 4,540 & $0,014 \mathrm{Cel} / \mathrm{día}$ & $49 \%$ \\
\hline
\end{tabular}

Fuente: García Martin Laura (5). 
Al realizar el ANOVA (95\%), se estableció que no existen diferencias significativas entre los tratamientos ensayados $(\mathrm{P}=0,795$; $\mathrm{gl}=1 ; \mathrm{F}=0,071$ ), lo cual indica que el tratamiento que brinda mejores resultados es aquel donde se utilizó $0,299 \mathrm{mg} / \mathrm{L}$ de acetato de sodio, ya que con esta concentración se obtuvo un mayor crecimiento y la mejor velocidad de crecimiento mejorando el crecimiento de la microalga que posiblemente produzca una mayor acumulación de astaxantina.
En cuanto a las concentraciones de astaxantina y clorofila expresadas en $\mu \mathrm{g} / \mathrm{mL}$, en el tratamiento con $0,299 \mathrm{mg} / \mathrm{L}$ de acetato de sodio (Figura 4), se pudo establecer que se encuentra mayor concentración de clorofila que de astaxantina ambas presentando su pico máximo en el día 20 , en donde presentan concentraciones de $28,706 \mu \mathrm{g} / \mathrm{mL}$ de clorofila y $2,530 \mu \mathrm{g} / \mathrm{mL}$ de astaxantina, comportamiento que se correlaciona con el recuento celular y absorbancias obtenidas.

Figura 4. Concentraciones de clorofila y astaxantina durante el montaje de 0,299 mg/L.

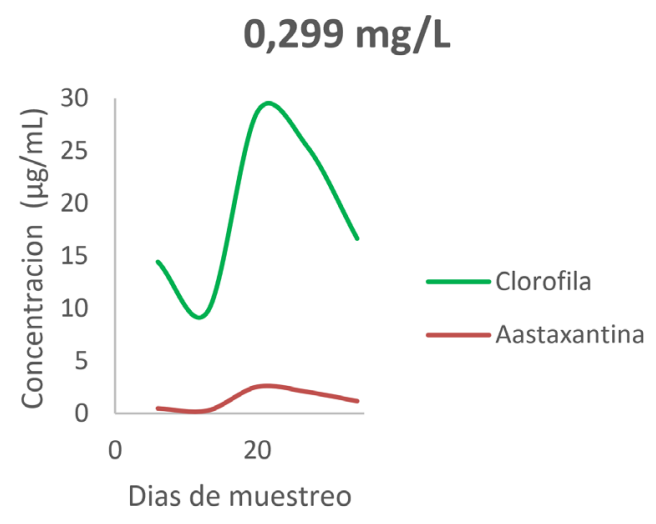

Fuente: García Martin Laura (5).

Figura 5. Concentraciones de clorofila y astaxantina durante el montaje de 1,6 mg/L.

$1,6 \mathrm{mg} / \mathrm{L}$

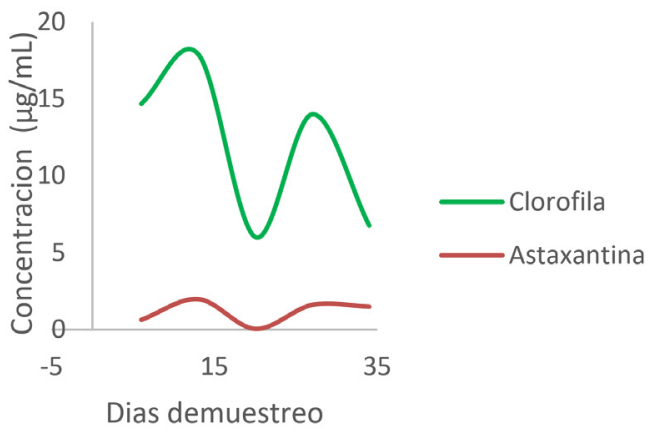

Fuente: García Martin Laura (5). 
En cuanto a las concentraciones de astaxantina y clorofila expresadas en $\mu \mathrm{g} / \mathrm{mL}$, en el tratamiento con $1,6 \mathrm{mg} / \mathrm{L}$ de acetato de sodio (Figura 5), se encontró mayor concentración de clorofila que de astaxantina ambas presentando su pico máximo en el día 13, en donde presentan concentraciones de $17,902 \mu \mathrm{g} / \mathrm{mL}$ de clorofila y $1,991 \mu \mathrm{g} /$ $\mathrm{mL}$ de astaxantina, comportamiento que se correlaciona con el recuento celular y absorbancias obtenidas.

Al realizar el ANOVA (95\%), se estableció que no existen diferencias significativas entre los tratamientos ensayados para la con- centración de clorofila $(\mathrm{P}=1 ; \mathrm{gl}=1 ; \mathrm{F}=0)$ y astaxantina $(\mathrm{P}=0,820 ; \mathrm{gl}=1 ; \mathrm{F}=0,054)$, lo que significa que en relación a concentración de astaxantina no existe diferencias en usar la concentración de $0,299 \mathrm{mg} / \mathrm{L}$ o usar la concentración de 1,6 mg/L de acetato de sodio, pues los dos van a presentar una concentración similar estadísticamente.

Durante cada montaje se llevó un registro fotográfico microscópico con el fin de evaluar la morfología de la microalga desde sus formas vegetativas hasta sus formas enquistadas (Tabla 3).

Tabla 2. Velocidad de crecimiento de los montajes analizados.

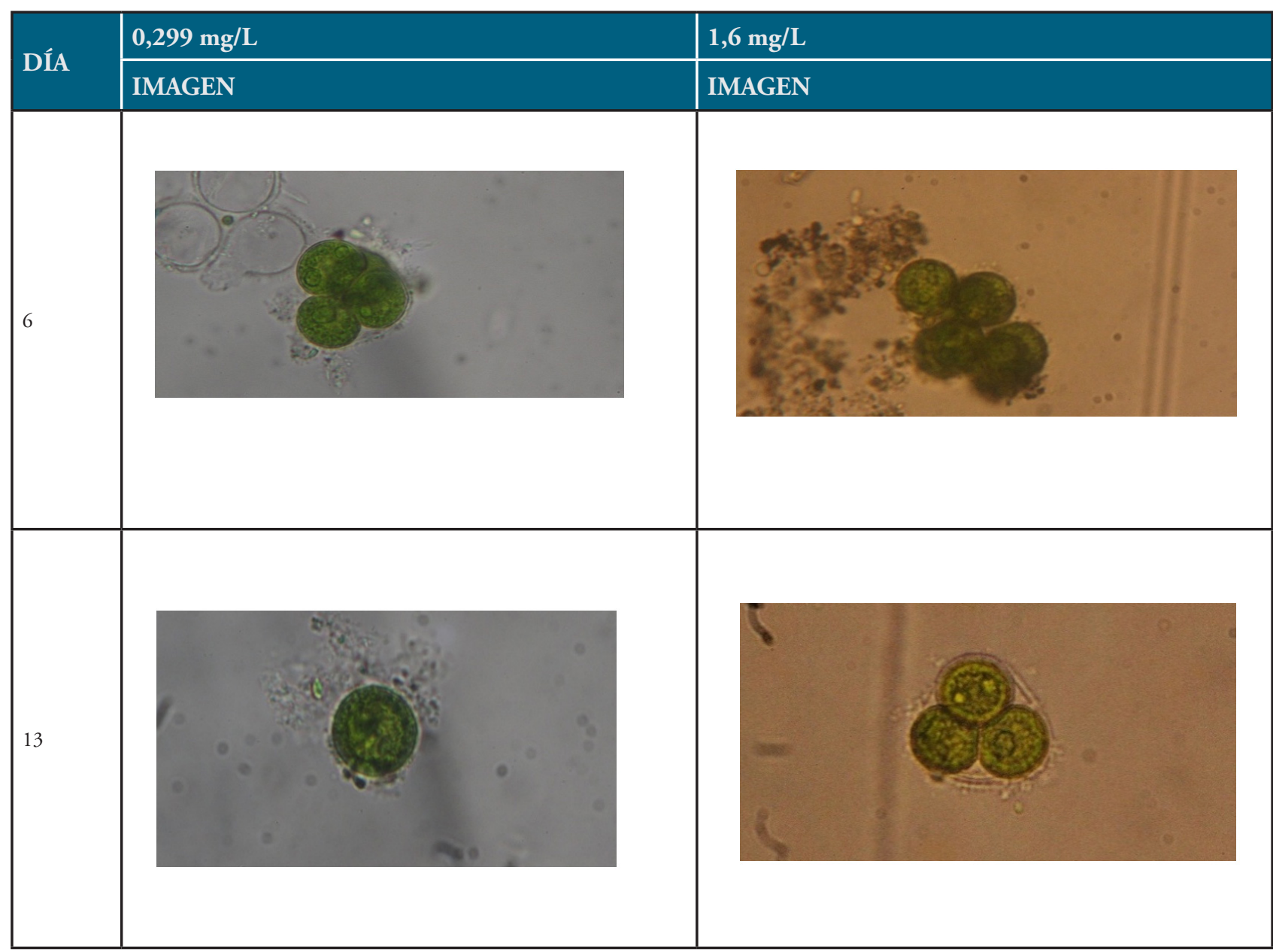




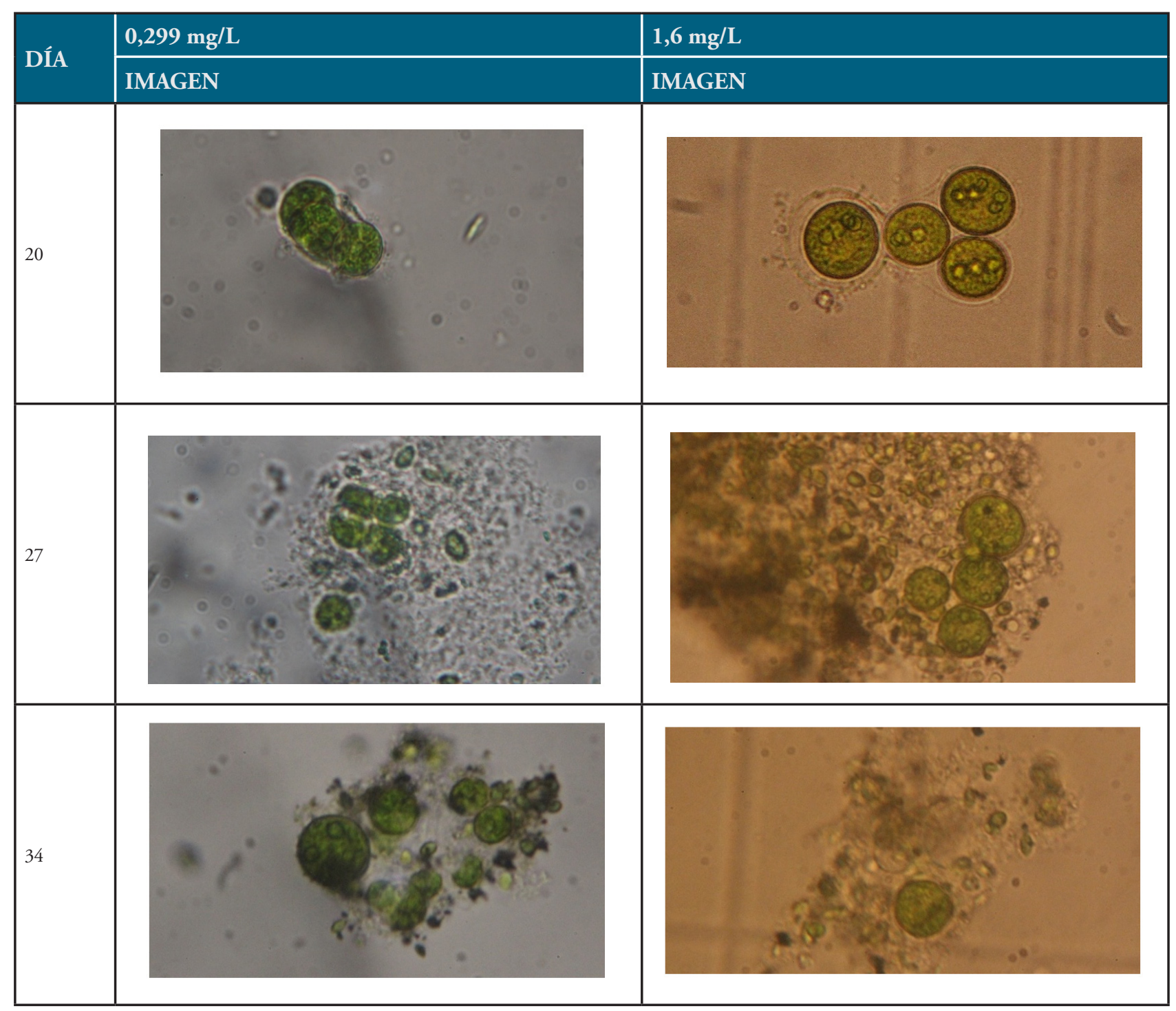

Fuente: Elaboración propia.

En cuanto al registro fotográfico de los dos tratamientos $0,299 \mathrm{mg} / \mathrm{L}$ y $1,6 \mathrm{mg} / \mathrm{L}$ de acetato de sodio, no existe alguna diferencia morfológica pues los dos presentaron formas celulares vegetativas, biflagelas y palmeloides sin acumulación de astaxantina, esto gracias a que, aunque si se hallaron concentraciones de astaxantina, al momento de realizar el registro fotográfico no se pudieron observar formas quísticas con acumulación de astaxantina.
Entre los días 13 y 20 fue en donde se observaron mayor cantidad de formas celulares vegetativas verdes sin flagelos, debido a que el crecimiento exponencial de $H$. pluvialis ha terminado e inicia su fase de deceso, mientras que en los días finales de los tratamientos se observaron formas celulares quísticas debido a que se iban agotando los nutrientes y estas formas son más resistentes (Tabla 4) $(1,2)$. 
Tabla 4. Comparativo entre el tratamiento de 0,299 mg/L y 1,6 mg/L de acetato sodio.

\begin{tabular}{|l|l|l|l|l|l|}
\hline \multirow{2}{*}{ [ ] ACETATO DE SODIO } & $\begin{array}{l}\text { RECUENTO } \\
\text { CELULAR } \\
\text { Cel/mL }\end{array}$ & PH & $\begin{array}{l}\text { [ ] DE } \\
\text { ASTAXANTINA } \\
\mu \mathrm{g} / \mathrm{mL}\end{array}$ & $\begin{array}{l}\text { [ ] DE CLOROFILA } \\
\mu \mathrm{g} / \mathrm{mL}\end{array}$ & $\begin{array}{l}\text { VELOCIDAD DE } \\
\text { CRECIMIENTO } \\
\text { Cel/día }\end{array}$ \\
\hline \multirow{2}{*}{$0,299 \mathrm{mg} / \mathrm{L}$} & $2,0 \times 104$ & 7,5 & 2,530 & 28,706 & 0,029 \\
\cline { 2 - 6 } & Día 20 & Día 34 & Día 20 & Día 20 & \multirow{2}{*}{0,014} \\
\hline \multirow{2}{*}{$1,6 \mathrm{mg} / \mathrm{L}$} & $3,5 \times 104$ & 8,6 & 1,991 & 17,902 & Día 13 \\
\cline { 2 - 5 } & Día 34 & Día 34 & Día 13 & & \\
\hline
\end{tabular}

Fuente: Elaboración propia.

El tratamiento con $0.320 \mathrm{~g} / \mathrm{L}$ de acetato de sodio y $1.28 \mathrm{~g} / \mathrm{L}$ de cloruro de sodio, adicionados desde el día 15 del estudio al medio RM (RM6), iluminación con lámparas blancas con $20 \mathrm{~h} \mathrm{luz} / 4 \mathrm{~h}$ oscuridad y $70 \mu \mathrm{E}$ $\mathrm{m}^{-2} \mathrm{~s}^{-1}$ de irradianza tuvo una velocidad de crecimiento de $1,018 \mathrm{cel} /$ día, seguido por el tratamiento RM3, el cual contenía acetato de sodio 1,6 g/L que se agregó desde el inicio y cloruro de sodio $6,4 \mathrm{~g} / \mathrm{L}$ que se adicionó el día 15 del estudio, usando la misma irradianza y fotoperiodo con una velocidad de crecimiento de 0,696 cél/día (Figura 6).

Figura 6. Curva de crecimiento T. RM3 Acetato de sodio 1,6 g/L + Cloruro de sodio 6,4 g/L y T.RM6 Acetato de sodio 0,320 g/L + Cloruro de sodio 1,28 g/L.

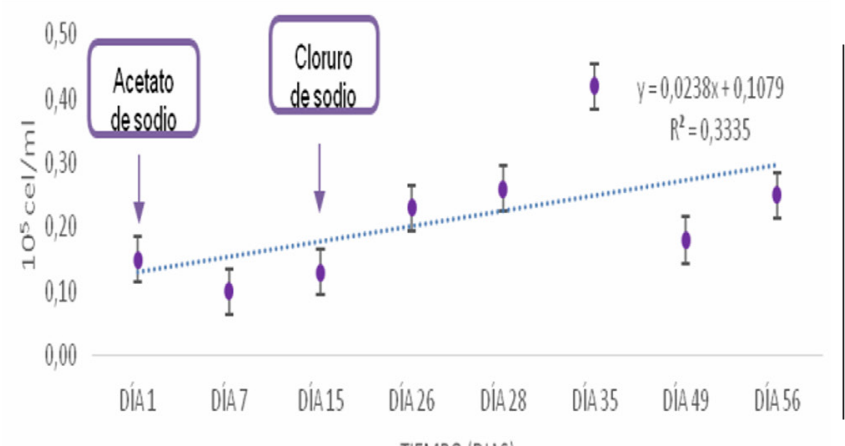

RM3 $\operatorname{TIEMPO}(D \mid A S)$

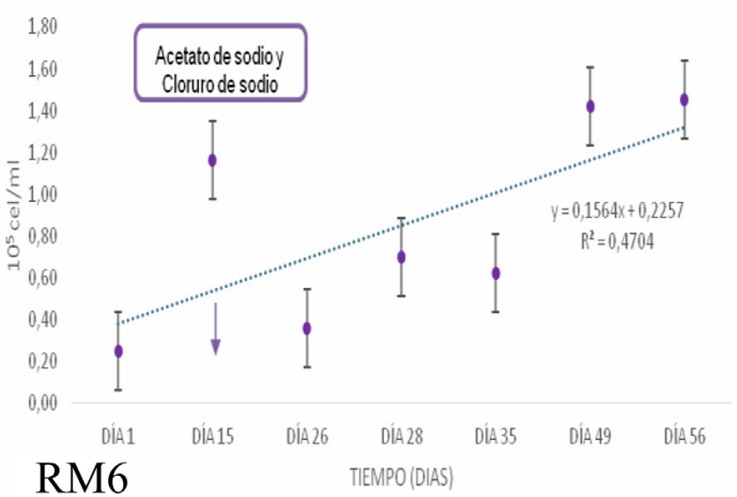

RM6

Fuente: Rodríguez, R. L. J. (30).

El análisis de varianza ANOVA (95\%) estableció con respecto al crecimiento celular que existen diferencias significativas $(\mathrm{F}=22,47$; $\mathrm{p}=0,025 ; \mathrm{gl}=5$ ) entre estos diferentes tratamientos. El tratamiento RM6 y RM4 fueron los que presentaron mayor crecimiento, $1,45 \times 10^{5} \mathrm{cel} . / \mathrm{ml}$ y $1,25 \times 10^{5} \mathrm{cel} . / \mathrm{ml}$, respectivamente. El control (RM1) tuvo un crecimiento de 2,69 x10 $\mathrm{cel} . / \mathrm{ml}$ (Figura 6).
En el estudio se observaron las dos fases por las que atraviesa la microalga $H$. pluvialis: fase vegetativa y fase roja debido a la combinación de factores de estrés. Se observan formas de palmella y células enquistadas (RM3) y aplanosporas (Figura 7). 
Figura 7. Cultivo H. pluvialis T. RM1, RM2, RM3, RM4, RM5 y RM6 Día 35.

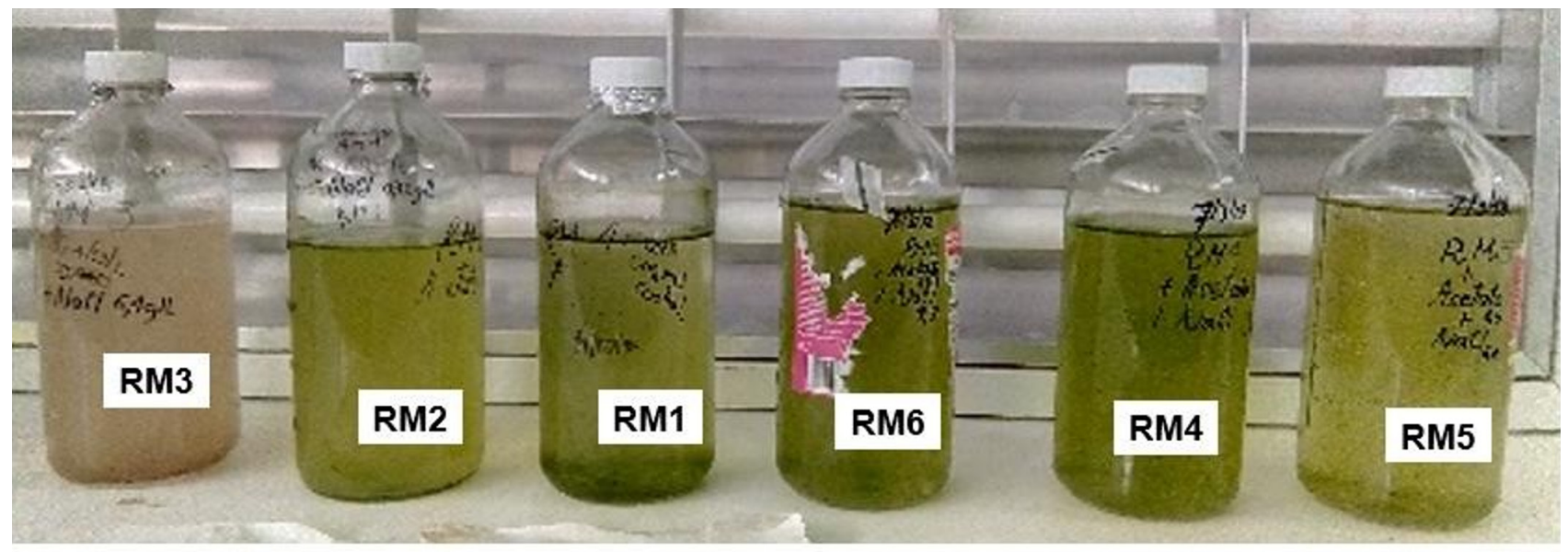

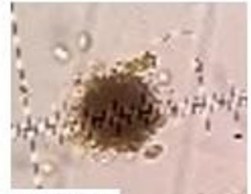

RM3
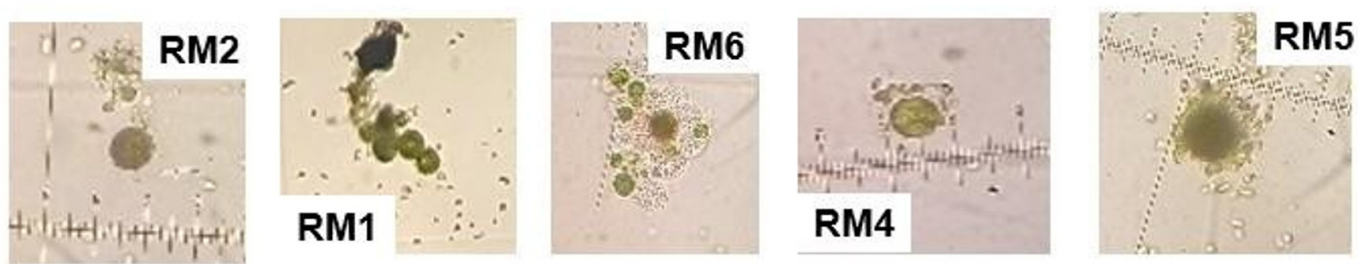

Fuente: Rodríguez, R. L. J. (30).

El tratamiento que presentó una mayor concentración de clorofila fue el RM6 obteniendo 0,245 microgramos/L, presentándose diferencias significativas entre tratamientos
$(\mathrm{F}=4,307 ; \mathrm{p}=0,003 ; \mathrm{gl}=5)$. La producción de clorofila se correlaciona con el crecimiento de la microalga porque al aumentar la biomasa incrementa el contenido de clorofila.

Figura 8. Concentración de clorofila (color verde) y astaxantina (color rojo) T. RM3 Acetato de sodio 1,6 g/L + Cloruro de sodio 6,4 g/L y T.RM6 Acetato de sodio 0,320 g/L + Cloruro de sodio 1,28 g/L
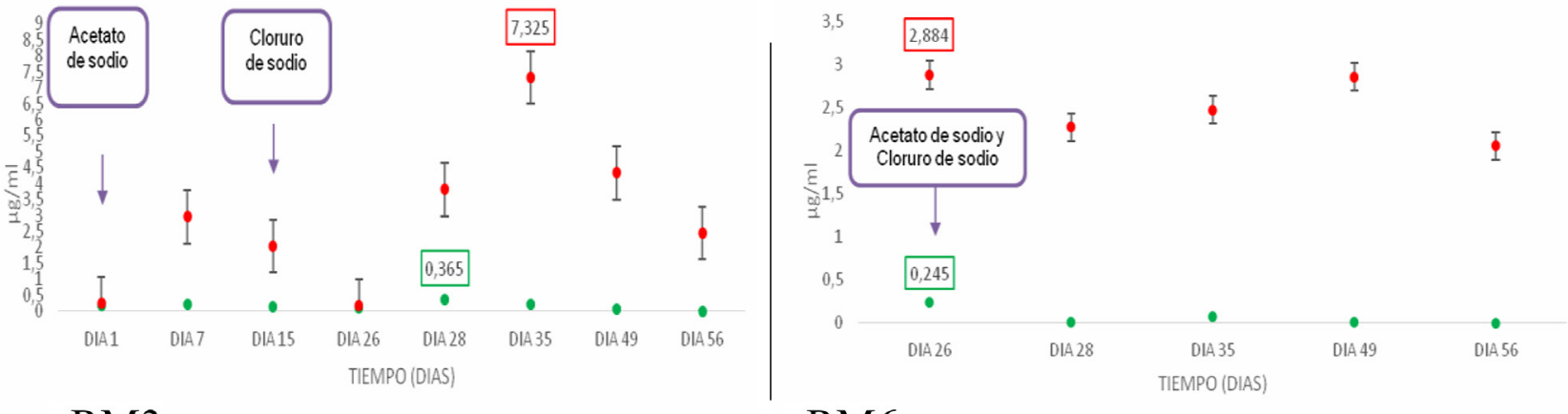

RM3 
El tratamiento RM3 presentó la mayor concentración de astaxantina de 7,325 microgramos/ml, utilizando una concentración de acetato de sodio 1,6 $\mathrm{g} / \mathrm{L}$ desde el inicio del estudio y cloruro de sodio de $6,4 \mathrm{~g} / \mathrm{L}$ que se agregó el día 15 del estudio (Figura 3). Al analizar los tratamientos realizados respecto a la astaxantina no hubo diferencias significativas $(\mathrm{F}=1,687 ; \mathrm{p}=0,165 ; \mathrm{gl}=5)$.

\section{Discusión}

A modo de suplir la necesidad de obtención de astaxantina a gran escala, se utilizó el biorreactor TEC-FERM de 5 L. El uso de biorreactores, para el escalamiento, con sistemas cerrados como el utilizado en este estudio, proporcionan mejores opciones para el crecimiento de la mayoría de microalgas, pues estos protegen el cultivo de la contaminación por microorganismos no deseados y de esta forma se permite que se tenga un control integral de las condiciones de cultivo $(3,4)$. Además de esto, tomando como base los resultados (4) y el trabajo (5), se tomó la decisión de utilizar el medio RM bajo las condiciones de estrés como lo son las diferentes concentraciones de acetato de sodio $(0,299 \mathrm{mg} / \mathrm{L} \mathrm{Y} \mathrm{1,6} \mathrm{mg/L),} \mathrm{pH}$ 6.8 , temperatura $20 \pm 1^{\circ} \mathrm{C}$, fotoperiodo $20 \mathrm{~h}$ luz blanca y 4 h oscuridad, aire filtrado, agitación fluctuante entre 90 y 180 rpm, todo con el fin de aumentar el crecimiento del inoculo inicial $1,0 \times 10^{4} \mathrm{Cel} / \mathrm{mL}$ y así inducir en la microalga la acumulación de astaxantina en su forma quística, con lo cual se pueda corroborar lo dicho por (6).
Del mismo modo muchos autores se han dedicado a investigar cuáles son los factores de estrés que ayudan a la adecuada acumulación de astaxantina, como el tipo, color y nivel de intensidad de luz, la agitación, el $\mathrm{pH}$ los cuales han arrojado buenos resultados como en (7), en donde se realizó cultivo en un fotobiorreactor tipo Airlift, manejando elevadas concentraciones de salinidad y alta intensidad de luz, como condiciones de trabajo y obtuvo una acumulación de astaxantina de $32,99 \mu \mathrm{g} / \mathrm{mL}(8)$, es por esto que en este estudio se utiliza el acetato de sodio como factor de estrés en diferentes concentraciones.

Existe la inquietud por investigar nuevos factores de estrés para $H$. pluvialis, como variar las concentraciones de acetato de sodio ya que este ayuda a promover el crecimiento celular $(6,4,9)$, otras investigaciones afirman que la concentración de acetato de sodio se debe controlar ya que con niveles inapropiados se puede generar la inhibición del crecimiento celular (9). En este estudio se trabajó con concentraciones de acetato de sodio $0.299 \mathrm{mg} / \mathrm{L}$ y $1.6 \mathrm{mg} / \mathrm{L}$ a diferencia de Niño, et al (10) que sometió a $H$. pluavilis, en el medio RM, a $0.310 \mathrm{mg} / \mathrm{L}$ de acetato de sodio obteniéndose un crecimiento celular de $7.55 \times 10^{5} \mathrm{Cel} / \mathrm{mL}$ y una velocidad de crecimiento de 0,092 Cel/día en 36 días, siendo el RM el que presentó mejor rendimiento en cuanto a crecimiento celular y obtención de astaxantina en comparación con los otros medios ensayados OHM, BBM (10). 
En el tratamiento con 0,299 mg/L de acetato de sodio, crecimiento de $2,0 \times 10^{4} \mathrm{Cel} /$ $\mathrm{mL}$ y velocidad de crecimiento de 0,029 Cel/día se obtuvo mejor tasa de crecimiento, lo que ayuda a la mayor acumulación de astaxantina, esto siendo muy consecuente con lo mencionado en Park et al (11), que realiza sus tratamientos con un fotobiorreactor tipo APBR y en sistema batch con las mismas condiciones de trabajo de este estudio y obtiene mejores resultados en el cultivo, tal vez debido a que en él se puede mantener un mayor control de las condiciones de trabajo (11), a diferencia del biorreactor TEC-FERM de $5 \mathrm{~L}$ utilizado en esta investigación.

Por otra parte, se puede decir que con las concentraciones de acetato de sodio $(0,299$ $\mathrm{mg} / \mathrm{L}$ y 1,6 mg/L) se obtiene mejor tasa de crecimiento, con recuentos de $2,0 \times 10^{4}$ $\mathrm{Cel} / \mathrm{mL}$ y $3,5 \times 10^{4} \mathrm{Cel} / \mathrm{mL}$ respectivamente, mientras que González et al (12), solo pudo obtener un aumento de $1.0 \times 10^{4}$ a $1,8 \times 10^{4} \mathrm{cel} / \mathrm{ml}$, lo que nos lleva a validar su postulado de que la suplementación de medios con acetato de sodio ayuda al incremento del crecimiento celular y a la formación de formas celulares quísticas $(12,13)$.

Del mismo modo aunque se obtuvo mayor recuento celular que algunos otros estudios en los cuales se realizó suplementación con acetato de sodio $(14,9)$, se observa que los recuentos celulares que se obtuvieron entre los días 15 y 20 del estudio para los dos tratamientos estuvieron en un rango de 2,0 $\mathrm{x} 10^{4} \mathrm{Cel} / \mathrm{mL}$ y $5 \times 10^{3} \mathrm{Cel} / \mathrm{mL}$ para el tra- tamiento con $0,299 \mathrm{mg} / \mathrm{L}$ y para el tratamiento con $1,6 \mathrm{mg} / \mathrm{L}$ se obtuvo un rango de crecimiento de $2,5 \times 10^{4} \mathrm{Cel} / \mathrm{mL}$ y $5 \times 10^{3}$ $\mathrm{Cel} / \mathrm{mL}$, esto se puede explicar de dos formas diferentes.

En la primera se puede decir que el microorganismo simplemente siguió su ciclo natural de crecimiento de aproximadamente 15 días $(1,2,13)$ como lo describe la literatura, o la segunda mencionada por (15) en donde afirma que la concentración de acetato deberá ser controlada a niveles apropiados con el fin de evitar la inhibición del crecimiento celular por acción del acetato de sodio, debido a que en su investigación con altas concentraciones de acetato de sodio 50 $\mathrm{Mm}$, obtuvo un rápido cambio morfológico de células vegetativa a forma quística y realizaba el blanqueamiento total de las células quísticas (9), lo que nos lleva a cuestionarnos si la adecuada concentración de acetato de sodio es de $0,310 \mathrm{mg} / \mathrm{L}(4)$.

Un factor a resaltar es que la mayoría de los estudios suplementados con acetato de sodio tienden a tener una mayor producción de biomasa que de astaxantina como lo observado en el presente estudio y es que así como se puede hacer referencia a los autores que han descrito anteriormente que las células de $H$. pluvialis solo requiere carbono como principal nutriente en la "etapa de crecimiento" y este puede ser suministrado diariamente por inyección de $\mathrm{CO}_{2}$ o por aire filtrado como en el presente estudio y con alta irradiación, fotoperiodos $20 \mathrm{~h}$ luz y 4 oscuridad, se proporciona mayor energía 
para la fijación fotosintética del carbono, lo que conduce a que haya una mayor tasa de síntesis de astaxantina (3); lo que lleva a deducir que en el estudio posiblemente no hubo la adecuada fijación fotosintética debido a que el biorreactor TEC-FERM presenta una especie de ventana pequeńa para su tamańo por donde entra la luz, lo que posiblemente, fue un factor determinante que evitó que se diera una elevada tasa de síntesis de astaxantina pero si una adecuada producción de biomasa.

Actualmente compañías dedicadas a la producción comercial de astaxantina a partir de microalgas (Cyanotech y Aquasearch), recurren a un sistema compuesto por dos etapas, la primera o también llamada "etapa verde" que consiste en producir biomasa verde en condiciones óptimas de crecimiento y la segunda o también llamada "etapa roja" que se inicia cuando la microalga es expuesta a condiciones ambientales adversas para inducir a la acumulación de astaxantina (3). Es aquí donde la suplementación con acetato de sodio puede ser implementada desde el día 15 , debido a que va a presentar un rendimiento adecuado en cuanto a la producción de biomasa y ayuda a la formación de quistes, los cuales son la forma celular adecuada para acumulación de astaxantina.

En cuanto a la concentración de astaxantina $(\mu \mathrm{g} / \mathrm{mL})$ en el estudio se obtuvo, para el tratamiento con $0,299 \mathrm{mg} / \mathrm{L}$ de acetato de sodio, la mayor concentración de astaxantina en el día 20 con $2,530 \mu \mathrm{g} / \mathrm{mL}$ y para el día 34 fue de $1,161 \mu \mathrm{g} / \mathrm{mL}$; mientras que el tratamiento con 1,6 $\mathrm{mg} / \mathrm{L}$ obtuvo una elevada concentración de astaxantina en el día 13 con $1,991 \mu \mathrm{g} / \mathrm{mL}$ y para el día 34 fue de $1,5 \mu \mathrm{g} / \mathrm{mL}$, resultados que pueden ser correlacionados perfectamente con el recuento celular obtenido para esos días. Por otro lado, en cuanto a la concentración de clorofila se pude decir que sucedió algo muy similar, ya que en el tratamiento de 0,299 $\mathrm{mg} / \mathrm{L}$ en el día donde se halló mayor concentración fue en el día 20 con $28,706 \mu \mathrm{g} /$ $\mathrm{mL}$ y en el día 34 fue de $16,637 \mu \mathrm{g} / \mathrm{mL}$; mientras que para el tratamiento con 1,6 $\mathrm{mg} / \mathrm{L}$ se halló una mayor concentración en el día 13 con $17,402 \mu \mathrm{g} / \mathrm{mL}$ y para el día 34 fue de $6,752 \mu \mathrm{g} / \mathrm{mL}$.

Aunque la concentración de clorofila fue disminuyendo a medida que se acercaba el final del estudio, la astaxantina iba aumentando su concentración, lo cual era lo realmente importante del proyecto, pero se observó que durante todo el estudio en los dos tratamientos realizados la clorofila $y$ astaxantina fueron inversamente proporcionales, lo que coincide con lo descrito por todos los autores consultados $(16,17,3)$. Es aquí donde se reafirma la situación planteada anteriormente en donde el estudio puede ser llevado en "etapa verde" hasta el día 20, ya que en este día se obtiene una buena producción de biomasa y después de este día se puede suministrar inyecciones directas de $\mathrm{CO}_{2}$, acetato de sodio y alta irradianza con fotoperiodos de $20 \mathrm{~h} \mathrm{luz}$ y $4 \mathrm{~h}$ oscuridad, con el fin de generar el estrés indicado para la iniciación de la "etapa roja”, y así las células inicien el verdadero estrés y de esta 
forma comience la acumulación de astaxantina y por lo tanto una buena obtención de la misma a futuro.

Las inyecciones de $\mathrm{CO}_{2}$ también pueden ser sustentadas gracias a que este ayuda a regular el $\mathrm{pH}$, lo que es un claro ejemplo de lo observado en el tratamiento con $1,6 \mathrm{mg} / \mathrm{L}$ de acetato de sodio, donde el aumento de $\mathrm{pH}$ inclinado hacia la alcalinidad, fue una posible causa de que la velocidad de crecimiento celular fuera menor, en comparación al tratamiento con $0,299 \mathrm{mg} / \mathrm{L}$, que presentó un $\mathrm{pH}$ más neutral y una mejor velocidad de crecimiento celular, razón por la cual se sugiere que la inyección directa de $\mathrm{CO}_{2}$ se sume a las condiciones de trabajo para los estudios de escalamiento de $H$. pluvialis.

Todos los resultados obtenidos hasta el día 20 se deben a la etapa de crecimiento o "etapa verde", generalmente dura de 9 a 20 días según la relación entre la biomasa celular y la actividad celular, lo cual se pudo evidenciar en el estudio debido a que en este tiempo fue en donde se obtuvo un mayor crecimiento celular. Luego llegando a la etapa de acumulación de astaxantina o "etapa roja", la morfología de aplanospora cambia por la disminución de nutrientes, de esta manera se deduce que para que el estudio presente mejores resultados, el estrés con el acetato de sodio puede ensayarse aplicándolo a partir del día 15 o 20 y no desde el primer día, ya que los estudios que han tenido mejores rendimientos han aplicado el estímulo desde el día 15 sin importar su fuente de carbono (17).
El en trabajo en el cual se utilizaron 5 tratamientos y un control (RM1), se estableció en las curvas de crecimiento de la microalga $H$. pluvialis, que la fase exponencial se presentó en diferentes días del estudio.

Teniendo en cuenta los resultados obtenidos por Niño et al (10), que obtuvieron una concentración celular máxima de $7,55 \times 10^{5}$ células/ml en medio RM en comparación con otros medios como OHM y BBM y de (18) con una concentración celular máxima de $9,50 \times 10^{5}$ células/ml en medio $\mathrm{RM}$; se seleccionó, el medio RM ya que es bien sabido que el medio de cultivo no solo afecta la productividad celular, sino también afecta la composición celular y el rendimiento de productos específicos. Utilizando este medio en nuestro estudio encontramos una concentra-

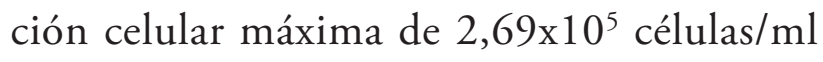
en medio RM1, siendo este el control. Estos resultados sugieren que el medio que provee los nutrientes adecuados para el crecimiento de $H$. pluvialis es el medio RM, similares resultados los obtuvo (19).

En el estudio donde utilizamos 5 tratamientos, se observó que el mayor conteo celular aparte del control, fue de $1,45 \times 10^{6}$ células/ $\mathrm{ml}$ en el tratamiento RM6 al cual se le adicionó $0,320 \mathrm{mg} / \mathrm{L}$ de acetato de sodio y 1,28 $\mathrm{mg} / \mathrm{L}$ de cloruro de sodio en el día 31 del estudio, concluyendo que estas concentraciones de sales no logran el suficiente estrés para inhibir el crecimiento celular.

Se realizó un análisis de varianza (ANOVA) de un factor (concentración celular) para 
los cinco tratamientos y el control encontrando diferencias significativas entre los tratamientos evaluados con una confianza del $95 \%$.

Es de aclarar que según el estudio de (20) donde se utilizó acetato de sodio (1 g/l) para comparar si se debía ańadir este compuesto junto con los nutrientes orgánicos al comienzo del cultivo como en la mixotrofia tradicional (TM), o al final de la fase logarítmica en modo fotótrofo como mixotrofia alternativa (AM), el estudio concluyó que el peso seco (DW), los pigmentos y especialmente el número de células en la mixotrofia alternativa (AM) fueron más altos que la mixotrofia (TM) tradicional (21).

El número de células en AM casi se duplicó de 21.7 a 42.9 × $10^{4}$ células $\mathrm{mL}$ durante 5 días de exposición a acetato de sodio, mientras que el aumento fue solo 1.2 veces en TM. Eso quiere decir que en próximos estudios podría ser más eficiente agregar el acetato de sodio de una forma mixotrófica alternativa o sea al final de la fase exponencial, ya que así se puede minimizar el riesgo de contaminación debido a la menor exposición de las células a las fuentes de carbono orgánico, sobre todo si el objetivo es obtener el máximo recuento posible de la microalga, sin embargo hay que tener en cuenta la concentración de acetato de sodio adicionado porque en el tratamiento donde se usó acetato de sodio de 1,6 mg/L desde el principio en el biorreactor TEC-FERM de 5 litros y la adición a los 15 días de cloruro de sodio mejoró la producción de astaxan- tina porque el acetato de sodio fue utilizado como fuente de carbono y generó mayor producción de biomasa que luego fue estresada con la combinación de cloruro de sodio y luz blanca alta con fotoperiodo de 20 h luz:4h oscuridad e irradianza de $70 \mu \mathrm{E}$, por el contrario en el tratamiento donde se utilizó combinados el estrés con acetato de sodio, cloruro de sodio y luz alta con el fotoperiodo mencionado, no se logró una buena biomasa ni una buena producción de astaxantina con una disminución del 71\% en su contenido. Observándose el impacto de la concentración de acetato de sodio de $1,6 \mathrm{mg} / \mathrm{L}$ sobre el crecimiento celular del H. pluvialis.

En los medios de cultivo macroscópicamente se observa un cambio de color rojizo en el medio RM3 desde el día 1 y medios RM2, RM5 y RM6 en el día 24 del estudio (Figura 7), que son congruentes con la observación microscópica realizada para analizar la evolución de la morfología de la microalga mediante su proceso de producción de astaxantina, observándose los cambios en morfología desde las formas vegetativas verdes hasta las aplanosporas y enquistadas con color rojo. Siendo estos resultados congruentes con el estudio de Su et al (22) donde al estresar la microalga con una alta intensidad de luz y acetato de sodio lograron evidenciar que a los dos días las células se volvían ligeramente rojizas indicando la transición a aplanospora (22).

Respecto a los resultados obtenidos de producción de astaxantina se logra evidenciar 
un aumento en el contenido de este pigmento, simultaneo con una disminución de la concentración de clorofila, congruente con los resultados obtenidos en (23) donde en su experimento después de 9 días de estrés, el contenido total de clorofila en todos los tratamientos fue un $90 \%$ menor que el de las células móviles verdes al inicio (23).

En el estudio de Wayama et al (24), se realizó una evaluación volumétrica, el resultado de estas imágenes 3D logró evidenciar que existían cambios drásticos en la transición entre la etapa verde y la etapa roja. En la etapa verde, los cloroplastos representaron el $41.7 \%$ del volumen total de células, mientras que el volumen total de astaxantina fue de $0.2 \%$ donde se observaron los cloroplastos altamente desarrollados en la periferia y pocos gránulos de astaxantina rodeando el núcleo. En la etapa roja, las gotas de aceite que contenían astaxantina predominaron con un 52\% y el volumen total de cloroplastos disminuyó a 9.7\% observándose gotas de aceite grandes en toda la célula, los cloroplastos estaban altamente degenerados y localizados en el espacio intermedio entre las gotas de aceite, que les daba una apariencia de red. Es importante aclarar que los cloroplastos no desaparecieron completamente, esto puede deberse a que serán utilizados en una recuperación rápida cuando las condiciones ambientales se reestablezcan y la descomposición de clorofila ha sido inducida por la deficiencia de nutrientes (24), lo cual también se observó en esta investigación.
Según los resultados obtenidos el medio RM3 al cual se le adicionó 1,6 mg/L de acetato de sodio desde el inicio del cultivo en el biorreactor TEC-FERM de 5 L. y la adición de 6,4 mg/L de cloruro de sodio el día 15 del cultivo presentó la mayor producción de astaxantina con una concentración de 7,3 microgramos/L, que es congruente con los resultados obtenidos por Domínguez et al (25) que utilizo $1 \mathrm{~g} / \mathrm{L}$ de acetato de sodio junto a iluminación continua y obtuvo una producción máxima de astaxantina de 98 $\mathrm{mg} / \mathrm{g}$ de biomasa y también con los resultados de Cifuentes et al (6) donde quiso descubrir condiciones óptimas para la producción de biomasa y astaxantina al someter la microalga a condiciones mixotróficas, es decir acetato de sodio con concentraciones de 4,8,12 mM bajo alta irradianza de luz y el cloruro de sodio al $0,8 \%$. Se obtuvo un contenido de astaxantina por peso seco de $10,3 \mathrm{mg}$ g-1 ( $1 \%$ p / p) y también se ha observado que la adición simultánea de acetato de sodio / $\mathrm{NaCl}$ en una concentración de $4.4 \mathrm{mM} / 17.1 \mathrm{mM}$ aumenta la producción de astaxantina (6).

Según el análisis de expresión de genes relacionados con la producción de carotenoides durante la inducción de estrés realizado por Vidhyavathi et al (26) nos dice que la adición de acetato de sodio y cloruro de sodio producen una transcripción temprana y regulación máxima positiva de genes como BKT ( $\beta$-caroteno cetolasa) que se encarga de la transformación de zeaxantina a adonixantina y adonixantina a astaxantina, desde tres días de estrés hasta tres meses 
después (26). Esto explicaría los resultados obtenidos en el estudio donde se observa una mayor producción de astaxantina al someter la microalga a estrés salino, ya que como se mencionó previamente la combinación de estos dos factores de estrés con la alta irradianza con luz blanca y fotoperiodo de $20 \mathrm{~h}$ luz:6h oscuridad, aumenta su producción, ya que estos carotenoides se acumulan en estructuras especiales tales como plastoglóbulos de plástidos o cuerpos lipídicos citoplasmáticos, jugando roles en prevenir el exceso de la energía lumínica del alcance de la maquinaria fotosintética (27-29).

\section{Conclusiones}

Los biorreactores de sistemas cerrados como el utilizado en este estudio, el biorreactor Tecferm de 5 Litros, proporcionan condiciones adecuadas para el crecimiento de la microalga $H$. pluvialis, ya que protegen el cultivo de la contaminación por microorganismos no deseados y de esta forma se permite que se tenga un control integral de las condiciones de cultivo, las cuales fueron establecidas según la revisión teórica realizada. El biorreactor se utilizó para producir biomasa de la microalga en la calidad y cantidad adecuadas conservando su morfología y también se produjo el colorante astaxantina.

El crecimiento de la microalga en el biorreactor con el tratamiento con $0,299 \mathrm{mg} / \mathrm{L}$ de acetato de sodio y las demás condiciones establecidas para el proceso fue de $2,0 \times 10^{4}$ $\mathrm{Cel} / \mathrm{mL}$ con una velocidad de crecimiento de 0,029 Cel/día, mientras que el tratamiento con 1,6 mg/L de acetato de sodio obtuvo un crecimiento celular de $3,5 \times 10^{4}$ $\mathrm{Cel} / \mathrm{mL}$ con una velocidad de crecimiento de 0,014 Cel/día, resultados obtenidos en los 34 días del estudio, lo que nos indica que el tratamiento con $0,299 \mathrm{mg} / \mathrm{L}$ de acetato de sodio presentó una velocidad de crecimiento 2 veces mayor al tratamiento con $1,6 \mathrm{mg} / \mathrm{L}$. No se observaron diferencias significativas entre tratamientos $(P>0.05)$.

En el tratamiento RM3, medio RM con una concentración de acetato de sodio de $1,6 \mathrm{mg} / \mathrm{L}$ y al cual se adicionó a los 15 días del cultivo cloruro de sodio en una concentración de $6,4 \mathrm{mg} / \mathrm{L}$ se produjo la mayor cantidad de astaxantina de $7,325 \mu \mathrm{g} / \mathrm{ml} \mathrm{a}$ los 29 días de tratamiento, correlacionado con las características macroscópicas y microscópicas obtenidas para este tratamiento. Esta investigación destaca por lo tanto la importancia de cultivar inicialmente la microalga utilizando el biorreactor Tecferm de 5 litros y después de su fase exponencial someterla a factores de estrés.

\section{Referencias}

1. Jeon YC, Cho CW, Yun YS. Combined effects of light intensity and acetate concentration on the growth of unicellular microalga Haematococcus pluvialis. Enzyme and Microbial Technology. 2006 Jul 3; 39(3):490-5.

2. Wang N, Guan B, Kong Q, Sun H, Geng Z, Duan L. Enhancement of astaxanthin production from Haematococcus pluvialis mutants by three-stage 
mutagenesis breeding. Journal of biotechnology. 2016 Oct 20; 236:71-7.

3. Wang, Junfeng, et al. Effect of initial biomass density on growth and astaxanthin production of Haematococcus pluvialis in an outdoor photobioreactor. Journal of applied phycology 2013. 25.1: 253-260.

4. Giannelli, Luca, et al. Effects of temperature on the astaxanthin productivity and light harvesting characteristics of the green alga Haematococcus pluvialis. Journal of bioscience and bioengineering 2015.119.3: 345-350.

5. García Martin Laura. Producción biotecnológica de astaxantina a partir Haematococcus pluvialis. 2018. Universidad Colegio Mayor de Cundinamarca. $86 \mathrm{p}$.

6. Cifuentes A, González M, Vargas S, Hoeneisen M, González N. Optimization of biomass, total carotenoids and astaxanthin production in Haematococcus pluvialis Flotow strain Steptoe (Nevada, USA) under laboratory conditions Biol Res. 2003. 36: 343-357.

7. Ramírez D. Evaluación del crecimiento y producción de astaxantina por Haematococcus pluvialis en un fotobiorreactor tipo airlift. Tesis. Universidad Nacional de Colombia. 2013. [Citado 2019 Febrero 25]. Disponible en: http://www.bdigital. unal.edu.co/11205/1/300061.2013.pdf

8. Tocquin P, Fratamico A, Franck F. Screening for a low-cost Haematococcus pluvialis medium reveals an unexpected impact of a low N/P ratio on vegetative growth. Journal of applied phycology. 2012 Jun $1 ; 24(3): 365-73$.

9. Wan, Minxi, et al. The effect of temperature on cell growth and astaxanthin accumulation of Haematococcus pluvialis during a light-dark cyclic cultivation. Bioresource technology 2014. 167: 276-283.

10. Niño-Castillo CM, Rodríguez-Rivera FC, Díaz LE, Lancheros-Díaz AG. Evaluation of Cell Growth Conditions for the Astaxanthin Production as of Haematococcus pluvialis Microalgae. Nova. 2017 Dec; 15(28):19-31.
11. Park, J. C., Choi, S. P., Hong, M. E., \& Sim, S. J. Enhanced astaxanthin production from microalga, Haematococcus pluvialis by two-stage perfusion culture with stepwise light irradiation. Bioprocess and biosystems engineering. 2014; 37(10), 20392047.

12. González MA, Cifuentes AS, Gómez PI. Growth and total carotenoid content in four Chilean strains of Haematococcus pluvialis Flotow, under laboratory conditions. Gayana. Botanica 2009. 66(1), 58.

13. Ranga R, Sarada A, Baskaran V, Ravishankar G. Identification of Carotenoids from Green Alga Haematococcus pluvialis by HPLC and LC-MS (APCI) and Their Antioxidant Properties. J. Microbiol. Biotechnol. 2009. 19:1333-1341

14. Shakhmatov AS, Pavlovskiy EV, Paukov AG. Desmid algae (Charophyta: Conjugatophyceae) of Ekaterinburg, Middle Urals, Russia. Folia Cryptogamica Estonica. 2018 May 29; 55:7-15.

15. Woong C,Jeon Y, Sang Y. Combined effects of light intensity and acetate concentration on the growth of unicellular microalga Haematococcus pluvialis. Rev Enzyme and Microbial Technology. Corea del Sur.2006 Julio. [accessed Mar 01 2018]. Disponible en: https://www.researchgate. net/publication/228353480_Combined_effects_ of_light_intensity_and_acetate_concentration on_the_growth_of_unicellular_microalga_Haematococcus_pluvialis.

16. Infant Santhose B, Elumalai S, Rajesh Kanna G. Airlift photobioreactor cultivation of a new strain of Haematococcus pluvialis collected from high altitude regions of Himalayas. International Journal of Science and Research. 2014; 3(10):2289-92.

17. Camacho Kurmen, J. E., González, G., \& Klotz, B. Astaxanthin Production in Haematococcus pluvialis under different stress conditions. Nova, 2013. 11(19), 94-104.

18. Imamoglu E, Sukan FV. Effect of Different Culture Media and Light Intensities on Growth of Haematococcus pluvialis. International journal of natural and engineering sciences. 2007; 1(3):5-9 doi: 10.1007/s11738-002-0058-9 
19. Leiton Arcos Y. A. Producción de Haematococcus pluvialis en el biorreactor Tecferm de $5 \mathrm{~L}$ en medios de cultivo RM y BBM. 2018. Universidad Colegio Mayor de Cundinamarca. $91 \mathrm{p}$.

20. Goksan T, Ak I, Gokpinar S. An alternative approach to the traditional mixotrophic cultures of Haematococcus pluvialis Flotow (Chlorophyceae). Journal of microbiology and biotechnology. 2010 Sep; 20(9):1276-82.

21. Infant Santhose B, Elumalai S, Rajesh Kanna G. Airlift photobioreactor cultivation of a new strain of Haematococcus pluvialis collected from high altitude regions of Himalayas. International Journal of Science and Research. 2014. 3(10):2289-92.

22. Su Y, Wang J, Shi M, Niu X, Yu X, Gao L, Zhang $\mathrm{X}$, Chen L, Zhang W. Metabolomic and network analysis of astaxanthin-producing Haematococcus pluvialis under various stress conditions. Bioresource technology. 2014 Oct 1; 170:522-9.

23. Vidhyavathi R, Venkatachalam L. Regulation of carotenoid byosinthetic genes expression and carotenoid accumulation in the green alga Haematococcus pluvialis under nutrient stress conditions. Journal of Experimental Botany. 2008. 59:14091418

24. Wayama M, Ota S, Matsuura H, Nango N, Hirata A, Kawano S. Three-dimensional ultrastructural study of oil and astaxanthin accumulation during encystment in the green alga Haematococcus pluvialis. PloS one. 2013 Jan 11; 8(1):e53618.

25. Domínguez-Bocanegra AR, Legarreta IG, Jeronimo FM, Campocosio AT. Influence of environmental and nutritional factors in the production of astaxanthin from Haematococcus pluvialis. Bioresource technology. 2004 Apr 1; 92(2):209-14.

26. Vidhyavathi, R., Sarada, R., \& Ravishankar, G. A. Expression of carotenogenic genes and carotenoid production in Haematococcus pluvialis under the influence of carotenoid and fatty acid synthesis inhibitors. Enzyme and Microbial Technology. 2009; 45(2), 88-93.

27. Amos R. Handboook of Microalga. Culture Biotechnology and applied Phycology. Blackwell publishing. India. 2005
28. Vásquez Perea, Y., Villamil Poveda, J., Sánchez Leal, L., \& Lancheros Díaz, A. Evaluación de un sistema de medio fijo como soporte para una película microbiana capaz de reducir Cr (VI) de lodos residuales de curtiembres. Nova. 2014. 12(21). https://doi.org/10.22490/24629448.996

29. Culture Colletion of Algae at The University at Austin (UTEX). Composición de medios para microalgas. [Internet]. . [Citado 2019 septiembre 20]. Disponible en: https://utex.org/products/volvox-medium

30. Rodríguez, R. L. J. Producción de astaxantina en Haematococcus pluvialis bajo efecto de factores de estrés como acetato de sodio y cloruro de sodio combinadas con alta intensidad de luz. 2019. Universidad Colegio Mayor de Cundinamarca. 